\title{
Using Space Time Visualization in Learning Environment Design
}

\section{Ben Rydal Shapiro}

Space, Learning \& Mobility Lab

Vanderbilt University

Nashville, TN 37203, USA

benrydal@gmail.com

\section{Abstract}

Space-time visualization is an established area of research and design. However, a significant gap in this work is how space-time visualization supports learning environment design in particular conceptual domains.

This paper introduces two new and generalizable types of interactive learning environment designs in different conceptual domains that use space-time visualization. The first is for museum studies and is designed for learners (typically museum curators, educators and designers) to learn about how museum visitors engage with exhibits in museum gallery spaces. The second

Permission to make digital or hard copies of part or all of this work for personal or classroom use is granted without fee provided that copies are not made or distributed for profit or commercial advantage and that copies bear this notice and the full citation on the first page. Copyrights for third-party components of this work must be honored. For all other uses, contact the Owner/Author.

Copyright is held by the owner/author(s).

CHI'17 Extended Abstracts, May 06-11, 2017, Denver, CO, USA

ACM 978-1-4503-4656-6/17/05.

http://dx.doi.org/10.1145/3027063.3048422 supports social studies education. Findings and discussion show how a) space-time visualization can be a powerful means to support specific types of learning environment designs and b) such efforts also can produce new types and uses of space-time visualization in particular settings.

\section{Author Keywords}

Space-time visualization; learning environment design; time geography; information design; interface design; interaction geography; design research; learning sciences; education

\section{ACM Classification Keywords}

H.5.m. Information Interfaces and Presentation (e.g. HCI): Miscellaneous; I.3.6 Methodology and Techniques; J.4 Social and Behavioral Sciences; J.5 Arts and Humanities

\section{Introduction}

Space-time visualization is an established area of research and design $[1,2,3,10]$. Moreover, it is a rapidly growing area due to new technologies $[2,6]$, new forms of urban mobility [3], open data resources [7] and the increasing need to gain insights and reveal patterns from complex data [6]. However, a significant gap in space-time visualization work is how space-time visualization supports learning environment design in particular conceptual domains. 
This paper illustrates the design of two types of learning environments in different conceptual domains that use space-time visualization to support learning. The first is an interactive learning environment that visualizes and allows for multi-modal analysis of museum visitor's physical movement, conversation, use of personal information devices and multi-perspective audio and video (if available) over space and time. This environment supports learners (typically museum curators, educators and designers) to learn about how museum visitors engage with exhibits in museum gallery spaces. The second is an interactive learning environment that allows learners to capture, compare and re-contextualize their "daily rounds" and "personal time-geographies" $[5,10]$. This environment supports social studies education.

This paper begins by reviewing relevant work in spacetime visualization and learning environment design. Subsequently, it illustrates and discusses each learning environment by 1 ) introducing the design context, 2) illustrating the environment in use through a figure and 3 ) discussing findings from its use. This paper concludes by synthesizing this work, discussing it's limitations and illustrating the need for future research in this understudied area.

\section{Relevant Work}

Two bodies of research concerning space-time visualization and learning environment design inform this work. With respect to space-time visualization, this work draws from time geography [5] and research concerning the use and advancement of the space-time cube and space-time cube operations [4]. Moreover, it also draws from the visualization and analysis of movement [3] and the use of flow maps by expert and non-expert audiences [8]. With respect to learning environment design, this work draws from a new genre of learning called "learning on the move" that focuses on how personal mobility and digital mapping technologies can be used to support new types of learning environment designs [10]. It also draws from conversation and interaction analysis research methods used in education [6] and design based research methods in the learning sciences that provide empirically driven ways to build, test and refine learning designs.

\section{Learning Environment 1: Museum Studies}

Design Context: This learning environment uses the Interaction Geography Slicer (IGS) to interactively visualize and allow for multi-modal analysis of people's (here museum visitors) physical movement, conversation, use of personal information devices and multi-perspective audio/video (if available) over space and time. This paper shows how this learning environment supports museum professionals learn about how their visitors engage with exhibits in museum gallery spaces. The empirical data of the learning environment (eg. visitor's movement, conversation and audio/video) was collected during IRB approved research funded by the National Science Foundation [9]. This research includes 1) 22 case studies of complete museum visits that captured continuous, multi-perspective audio and video records of visitor mobility and interaction and 2) audio, video and survey based data from design sessions with professional museum curators, educators and designers. Figure 1 below shows aspects of the learning environment during one design session with museum professionals. Subsequently, this figure is used to discuss findings that advance space-time visualization. 
Figure 1: The bottom left image of the figure shows a group of museum curators, educators and designers using the Interaction Geography Slicer (IGS) to study how their visitors engage with exhibits in museum gallery spaces. Different visitor groups and gallery spaces can be selected and compared. The large top image provides a detailed view of what they are looking at, which is the simultaneous movement of a family of 5 (a mother, 2 sons, their sister and her fiancé) in one museum gallery space. Color designates individual family members. The timeline $Y$-axis corresponds to the vertical dimension of the floor plan. Line pattern corresponds to the horizontal dimension of the

floor plan. The bottom right image displays video (from a camera worn by family member Lily) selected by a museum curator at a point in space and time when the family is gathered together at an exhibit dedicated to Maybelle Carter. Software is written and will be made available by Ben Rydal Shapiro using JavaScript \& p5.js. Source: Copyright (c) by Ben Rydal

Shapiro. Reprinted by permission.

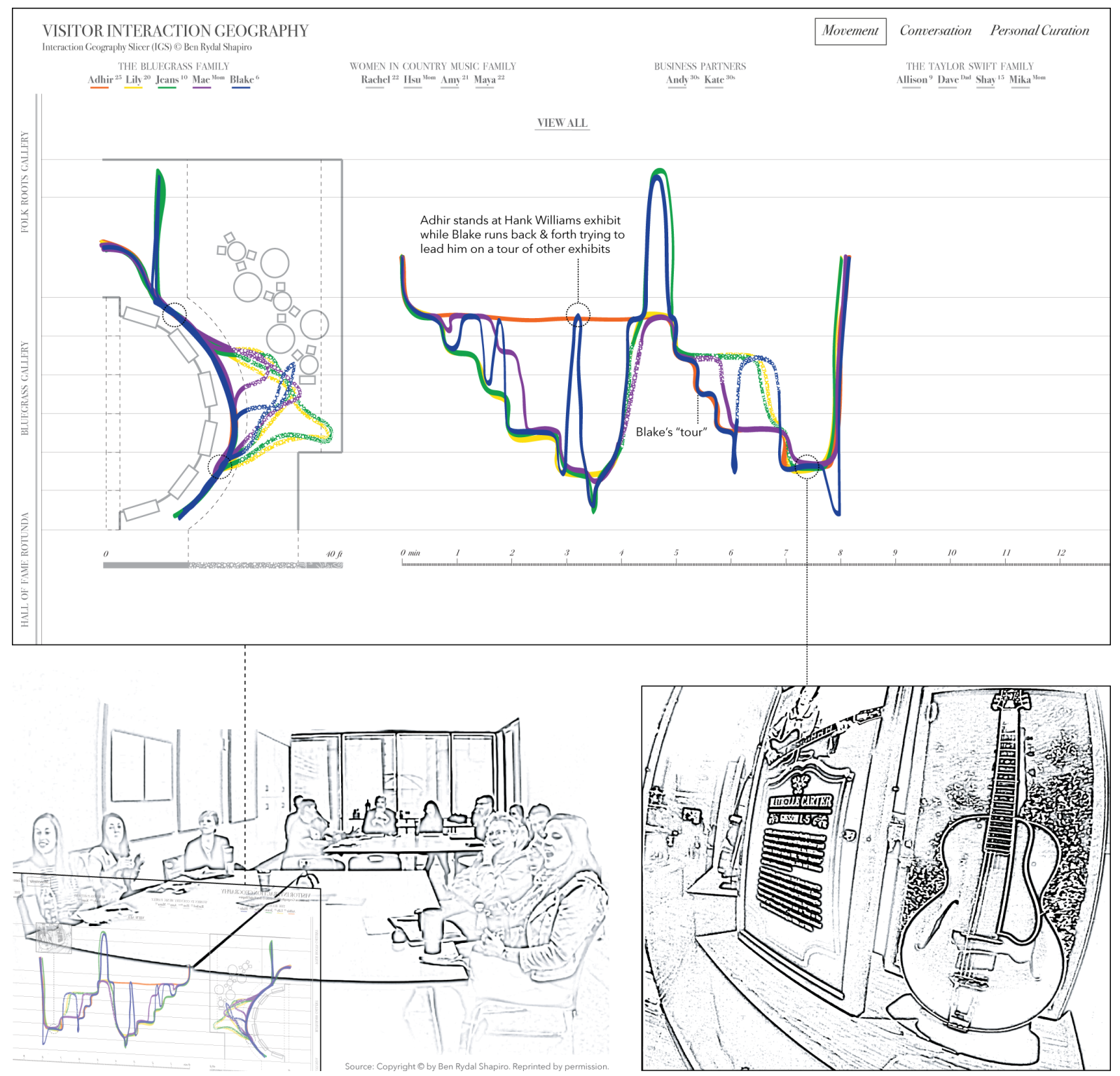


Findings: Interaction and conversation analysis of audio and video records in addition to post surveys of people using the Interaction Geography Slicer show that, as a learning environment, it helps learners see museum visitors in new ways and challenge idealized models of museum visitors as relatively passive consumers of intended design. For example, the previous figure captures a moment where many learners realize that a young child's rapid movements across a gallery space are not childish behavior as traditionally conceived but rather very intentional efforts to learn. In this case, the young child is 6-year-old Blake (the blue path in the figure) who runs back and forth across the museum gallery trying to lead Adhir who is standing at an exhibit dedicated to Hank Williams (straight orange path from minutes 0-5) on a tour of other exhibits. Blake is finally successful at minutes $5-6$ indicated by their intertwined movement paths.

Likewise, the learning environment necessitated advancements in space-time visualization that contribute to human-computer interaction research. For example, as shown in the previous figure space-time visualization was used to interact with complex multiparty audio and video (eg. by selecting and playing) in ways that further existing research [4] and in a new context (eg. a museum). There is not room in this paper to fully illustrate these capabilities however, it is important to note that this learning environment also necessitated advancing space-time visualization to visualize conversation and the use of personal information devices. Figure 2 below shows one way conversation is visualized. It extends the previous figure by showing the conversation of the same family (the Bluegrass Family) in the same gallery space (the Bluegrass Gallery).

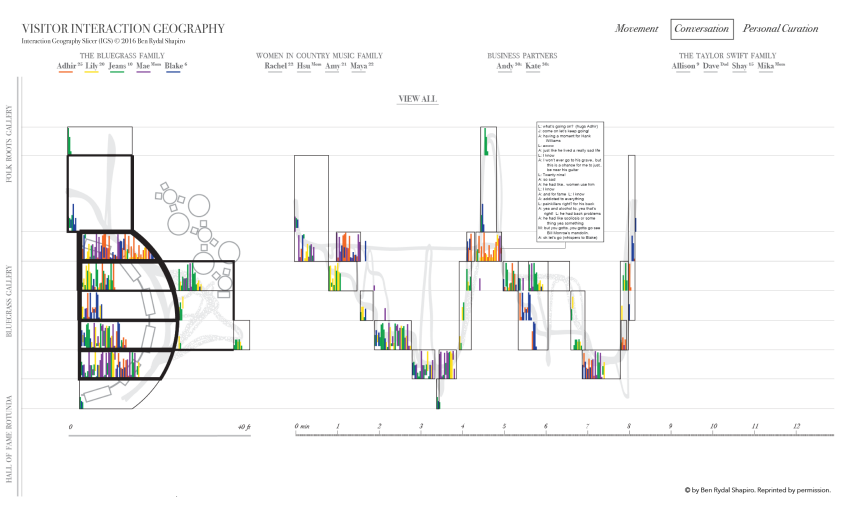

Figure 2: Space-time visualization of the Bluegrass Family's conversation in the Bluegrass Gallery. Conversation organizes transcribed talk colored by speaker in space and time and groups topically related talk into conversation "boxes". Thicker boxes on the floor plan show repeated conversations in the same area of space. Source: Copyright (c) by Ben Rydal Shapiro. Reprinted by permission.

\section{Learning Environment 2: Social Studies}

Design Context: This learning environment allows learners to capture, compare and re-contextualize their "daily rounds" and "personal time-geographies" [5, 10]. A central part of this learning environment is a set of dynamic visualization tools that allow learners to visualize, interact and layer digital maps, large-scale data sets, imagery and personal mobility in multiple 2D \& 3D representational forms. Figure 3 below shows how part of this learning environment is used in a university social studies course with 21 undergraduate and graduate students to teach and support conversations about human geography, new digital mapping technologies as well as student's experiences with race and diversity in their daily lives. Subsequently, this figure is used to discuss specific findings that advance space-time visualization research. 
Figure 3: The bottom left image shows an in-class activity with university students. At the front of the classroom one group of students analyze all 21 students personal mobility (collected prior to class using cell phones) over the "racial dot map" where color indicates race. The large top image magnifies their screen and shows students highlighting the "University Bubble" that conditions their daily lives and "Highway I-40" that was built in the 1960 s through a vibrant African American neighborhood destroying a famous music row known as Jefferson Street where Jimi Hendrix and Ray Charles once played. The bottom right image magnifies the screen of students using a "space-time cube" to display their movement on a map and as it extends upwards in time over a period of 3 days. Software is written and will be made available by Ben Rydal Shapiro using the Processing Programming Language and Unfolding Maps Library. Source: Copyright (c) by Ben Rydal Shapiro. Reprinted by permission.

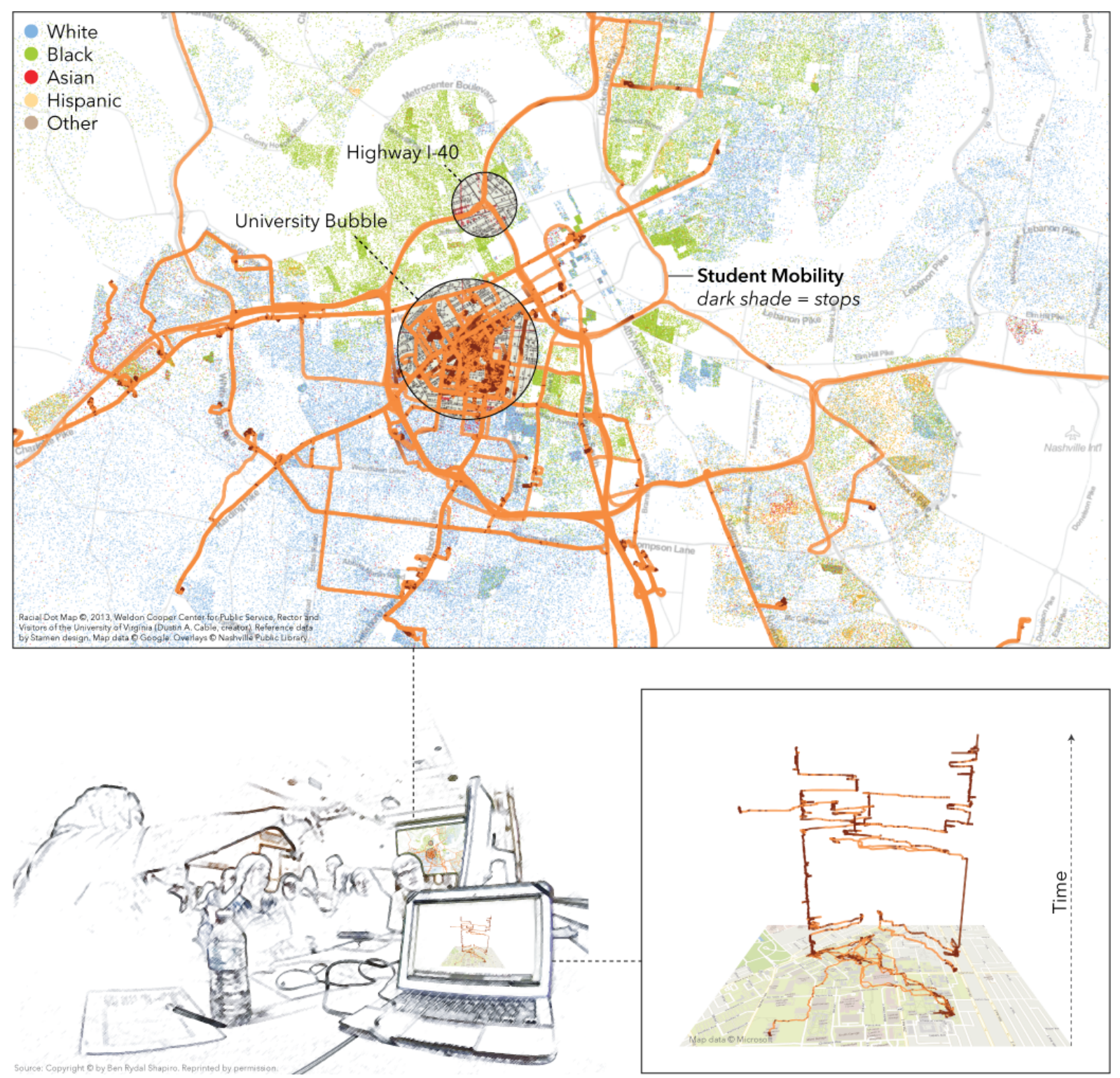


Findings: The learning environment makes personal and aggregate (eg. the whole class) daily rounds and time geographies "experiential and relevant" [10] and personalizes large scale data sets such as the racial dot map in a manner that supports learning about issues of power, storytelling and representation important to social studies education. For example, the figure above illustrates students exploring their lived experiences of physical places (eg. the university bubble) in comparison to the represented space of the racial dot map. This allowed them to see the spatial distribution of cultural assets important to human geography perspectives. It also allowed them to see why they rarely interact with particular neighborhoods and why there were extreme differences between undergraduate and graduate student experiences (eg. undergraduates were bound to the university bubble). Second, the environment helps learners learn about the possibilities of new forms of digital mapping and data visualization technologies and open data resources. For students shown in the figure above (some of whom are preservice social studies teachers), it helps them learn about how they can use these emerging technologies and resources in their own school and university social studies classrooms.

\section{Conclusion \& Future Work}

Space-time visualization provides a powerful means to support learning environment design. Likewise, learning environment design is an exciting area of research that can advance space-time visualization research. Future research should address a number of limitations and needs in this early work such as how learning activities and visualization can integrate seamlessly and how this work can be sustained in specific contexts.

\section{References}

1. W. Aigner, S. Miksch, H. Schumann, and C. Tominski. 2011. Visualization of time-oriented data. Springer, Berlin, Germany.

2. N. Andrienko and G. Andrienko. 2005. Exploratory Analysis of Spatial and Temporal Data: A Systematic Approach. Springer-Verlag New York, Inc., Sankt Augustin, Germany.

3. N. Andrienko and G. Andrienko. 2013. Visual analytics of movement: an overview of methods, tools and procedures. Information Visualization 12 1: 3-24.

4. B. Bach, P. Dragicevic, D. Archambault, C. Hurter, and C. Sheelagh. 2014. A Review of Temporal Data Visualizations Based on Space-Time Cube Operations. In IEEE Eurographics Conference on Visualization. Swansea, Wales, UK.

5. Torsten Hagerstrand. 1970. What about people in regional science? Papers in Regional Science, 24, 1: 6-21.

6. Brigitte Jordan and Austin Henderson. 1995. Interaction analysis: Foundations and practice. The Journal of the Learning Sciences, 4,1: 39-103.

7. Tamara Munzner. 2014. Visualization Analysis and Design. CRC Press.

8. T. Nagel, E. Duval, and A. Vande Moere. 2012 Interactive exploration of geospatial network visualization. In $\mathrm{CHI}$ '12 Extended Abstracts on Human Factors in Computing Systems (CHI EA '12). ACM, New York, NY, USA, 557-572.

9. Ben R. Shapiro and Rogers Hall. 2016. Engagement within Interest Driven Learning Environments. In Proceedings of the $2^{\text {nd }}$ annual Terrains symposium. University of Melbourne, 80-86.

10. Katie H. Taylor and Rogers Hall. 2013. Countermapping the neighborhood on bicycles: Mobilizing youth to reimagine the city. Technology, Knowledge and Learning, 18, 1-2: 65-93. 